\title{
Women exposed to intimate partner violence: a Foucauldian discourse analysis of South African emergency nurses' perceptions
}

\author{
Anna van der Wath
}

Nursing Science Department, Prinshof Campus, University of Pretoria, Private bag X20, Hatfield, Pretoria, Gauteng 0028, South Africa.

\begin{abstract}
:
Background: Emergency nurses' understanding and interpretation of intimate partner violence influence the care they provide to women exposed to intimate partner violence.

Objectives: The aim of this study was to uncover discourses that may help understand emergency nurses' responses towards women exposed to intimate partner violence

Materials and methods: This study used a qualitative design to explore emergency nurses' discourses. Purposive sampling was used to select 15 participants working at an emergency unit in a public hospital in South Africa. Data were collected through three focus group discussions comprised of five emergency nurses each. Foucauldian discourse analysis was used to analyse the transcribed data.

Results: Four themes emerged from the focus group discussions: (1) strong women subject themselves to societal expectations and endure intimate partner violence, (2) women are vulnerable and powerless against intimate partner violence, (3) intimate partner violence is a private and secret phenomenon, and (4) emergency nurses have limited scope to intervene when they encounter women exposed to intimate partner violence.

Conclusion: Emergency nurses are in a position to intervene in intimate partner violence through portraying a non-judgmental approach that lay the foundation for disclosure, supporting women to change their intimate partner violence (IPV) situations, documentation, referral and safety planning.

Keywords: Intimate partner violence, Foucauldian discourse analysis, emergency nursing.

DOI: https://dx.doi.org/10.4314/ahs.v19i2.7

Cite as: van $\operatorname{der} W$ ath $A$. Women exposed to intimate partner violence: a Foucauldian discourse analysis of South African emergency nurses' perceptions. Afri Health Sci.2019;19(2): 1849-1857. https:/ / dx.doi.org/10.4314/abs.v19i2.7
\end{abstract}

\section{Introduction}

Based on a systematic review, Sprague et $\mathrm{al}^{1}$ estimated the lifetime prevalence of any type of intimate partner violence (IPV) to be $40 \%$ in emergency medicine. Emergency nurses (ENs), often the first point of contact, are in a unique position to assist women exposed to IPV ${ }^{2}$. In

\section{Corresponding author:}

Anna van der Wath,

Nursing Science Department, Prinshof Campus,

University of Pretoria, Private bag X20,

Hatfield, Pretoria, Gauteng 0028, South Africa.

Email: annatjie.vanderwath@up.ac.za fact, all healthcare providers should be able to identify women who are exposed to IPV, provide supportive care and appropriately refer these women ${ }^{3-5}$. In spite of the mentioned expectations, ENs still experience considerable barriers to identify and manage women exposed to IPV appropriately ${ }^{6-7}$.

Barriers leading to healthcare providers being unprepared to appropriately care for women exposed to IPV include time constraints, women denying IPV ${ }^{8}$, providers' lack of organisational support and lack of knowledge about the extent of IPV ${ }^{9}$. Healthcare providers may also perceive IPV as a social problem belonging to the social work domain, or as a personal problem with indi- 
vidual attributes and responsibilities, for example, Finnish healthcare providers perceived IPV to be outside of their core tasks, only to be addressed if a woman raises the topic ${ }^{10}$. Understanding their challenges, may help to facilitate a responsible approach from healthcare providers ${ }^{10}$. In South Africa, ENs experience distress when dealing with IPV survivors which may affect the care provided to these women ${ }^{11}$. The distress may stem from healthcare providers' stereotypical and even distorted perceptions about IPV. The perception that IPV is rare, may cause healthcare providers to overlook most of these women ${ }^{12}$. Healthcare providers may encourage women to leave abusive relationships, perceiving their advice to be the best option, unaware of the risks women face when leaving such a relationship. The misperception that women cannot make appropriate choices leads to disempowerment and "replicates the patriarchal attitudes that abused women are trying to escape" ${ }^{\text {"13. }}$.

Further exploration of the pervasive discourses of IPV in a specific society and their influence on healthcare providers' care to women exposed to IPV is required ${ }^{2}$. Foucauldian discourse analysis (FDA) is centered on the premise that "practices obey certain rules"14. Discourses constitute knowledge about a particular topic at a particular time in history which govern the social construction of reality. All social practices entail meaning, and different meanings shape and govern conduct ${ }^{14-16}$. The discourses which influence reality are tied into complex networks of power and knowledge. Both power and knowledge have a profound impact on women exposed to IPV ${ }^{17}$.

Sovereign or pre-modern power relationships govern the interactions between the abuser and the victim, while social surveillance or modern power relationships govern the victim's interaction with the broader community ${ }^{17}$. Women exposed to IPV often form the focus of much scrutiny from "helping" institutions, such as the police, healthcare and legal services ${ }^{17}$. The way in which these institutions provide help are shaped by discourses of individuals within those institutions. The aim of this study was to uncover some of the prevailing discourses that may help understand ENs' responses towards women exposed to IPV.

\section{Methods}

\section{Research setting}

The study was conducted in the emergency unit of a public district hospital in an urban area in South Africa. Most healthcare users in South Africa use public healthcare as only $16 \%$ of the population can afford better resourced private healthcare ${ }^{18}$. Women exposed to IPV visit the unit for treatment of problems directly or indirectly related to IPV. No statistics were available about the number of women who experienced IPV that visited the unit.

\section{Sampling}

The study was introduced to the unit manager and the nurses working on two different shifts. Nurses who indicated their willingness to participate in the study based on their experience and knowledge of IPV were purposively selected $^{19}$. Fifteen ENs from different categories - professional, enrolled and assistant nurses - participated in the study.

\section{Data collection}

Approval was obtained from the Research Ethics Committee, Faculty of Health Sciences, University of Pretoria (No. 276/2015). After participants provided written informed consent, data were collected during three semi-structured focus group discussions conducted in January 2017. Participants were asked about their perceptions of IPV and the way they provide care to women exposed to IPV. Through the use of communication skills such as probing questions and clarification, rich descriptions were obtained ${ }^{19}$. Focus groups lasted between 45 to 60 minutes. Participants were requested to keep the focus group discussions confidential, and numbers, instead of names, were used to identify participants.

\section{Data analysis}

The data were analysed manually using FDA as described by Wiggins and Riley ${ }^{20}$. Key themes were identified from the transcribed focus groups. An overarching term was used to describe each theme. All sections of themes were marked to produce a series of extracts. Discourses were identified by sorting extracts according to the different and particular ways of talking about the themes. The following questions were asked to uncover the discours- 
$\mathrm{es}^{21-23}$. What do participants say (or do not say) about IPV and women exposed to IPV? What constitutes participants' reality of caring for women exposed to IPV? How was this reality constructed? How do discursive constructions open up or close opportunities for ENs to intervene when they encounter women exposed to IPV? What relations of power and knowledge do these discursive constructions rely on?

\section{Results}

The analysis revealed discourses that inform ENs' practices when they encounter women exposed to IPV. The discourses are reflected in four themes, namely (1) strong women subject themselves to societal expectations and endure IPV, (2) women are vulnerable to and powerless against IPV, (3) IPV is a secret and private phenomenon, and (4) ENs have limited scope to intervene when they encounter women exposed to IPV.

\section{Strong women subject themselves to societal expec- tations and endure intimate partner violence}

ENs described women as strong when they subject themselves to societal expectations and endure IPV by keeping quiet and staying in the relationship, often for the sake of their children.

One of the participants in Focus group 1 described an incident where a woman who was beaten by her partner chose not to wait to be referred to the social worker as "ber son was not taken care of." The participant justified the woman's choice as a desirable practice that any woman would have followed; that is to put her children's needs first. The woman's sacrifice was objectified as a virtue: "There's no women who will just leave her kids...the kids come first with us. With a serious injury, you get home, you just have to take care of the kids. So you must have strength, to do that... and try to ensure their children are safe and have a home".

A woman who subjects herself to male power and stays in an abusive relationship is seen as a real (strong) woman. This discourse is embedded in certain communities and governs the conduct of women in a relationship, as exemplified by a participant in Focus group 3: “...in our communities, we grow up with the impression that sometimes we have to go through that abuse in order for you to be seen as a woman. Women need to be strong, whatever is happening you need to be able to handle that, so it's seen that as women, we even judge each other'. Participants indicated how this discourse limits a woman's options to address IPV since she is expected to comply with societal expectations. There was a lively discussion in Focus group 2 as one participant opposed and resisted the practice of parents who "tell you: "Stay!" in an abusive relationship by describing these parents as "the wrong support system". The participants also provided some clues as to how the discourse came about. Parents ("especially mothers") advise their daughters to follow their example. The participants laughed and showed acknowledgement as they recognised the voices of the parental generation in the next extract: "You can't leave that man...me and your father have stayed in this house, you see how big is the house now, because I have been standing in, I am a strong woman, you just keep quiet. If he comes back at one o'clock in the evening just keep quiet, don't ask bim..."

Participants alluded that women exposed to IPV might choose not to follow suggestions from ENs to get help, due to a lack of other options, often saying "No, he will kick me out, where do I go?" This confirmed the discourse that a strong women will stay and endure the IPV as resistance will put her in a vulnerable position, where she might become a burden to others as explained by a participant in Focus group 1: "Sometimes the community thinks like: 'Why did you leave? You should have stayed. You are now a burden.' When you go [back] to your family you'll feel like a burden."

\section{Women are vulnerable to and powerless against inti- mate partner violence}

Participants shared the perception that it is almost impossible for a woman to escape from an abusive relationship. Women were described as vulnerable and powerless: “... most women are vulnerable and weak, they are", which contradicts the first discourse where women who subject themselves to male abuse are seen as strong women. Abusers rely on the weak and dependent nature of their partners, who are trapped by a lack of resources, to maintain the web of power in the relationship: "I think it is a case of somebody who want to feel power in the relationship over the other person, then the only way they can do it is to make that somebody feel weak".

ENs treat the visible injuries resulting from IPV and they "feel bad, because when she goes back the same things is going to happen again." The woman is discharged to the same situation where IPV will repeat itself, as explained by a participant in Focus group 3: "It doesn't get better, be will do it again... it doesn't get better." Participants in Focus group 2 
alluded to the long-term mental health outcomes of IPV, "most of them they end up being psychotic." ENs also observe the despair and powerlessness of women exposed to IPV when they are brought in after a suicide attempt as in the next two extracts: "...they become bysterical... they just want to get out of their house... some attempt suicide"; "...the lady who overdosed on anti-hypertensive treatment because the husband hit her'.

The participants shared the women's fears that their children's relationships would be governed by the power structures maintaining the web of IPV: "I think they're scared. If there's a boy in the family, he'll end up like the father, if there's a girl, she might end up saying she doesn't want to get married'.

Participants felt that as women they are just as prone to IPV: "We are women, we think, what if we were in the same position?' Participants explained how their encounters with women exposed to IPV affect the way in which they see their own relationships. The extract illustrates the fine power balance in a relationship that women must always be cautious not to disturb: "Yes, in most cases, you judge yourself, after talking to your partner in a rough way, you do some introspection and realise: I was not supposed to answer like that, but I did due to the anger I experience at work.' You react the wrong way, thinking: 'What if he abuses me like that? I won't take it."'

The subject position that women occupy in relationships is illustrated in one of the causes of IPV suggested by participants, namely, "cheating...most of the time." Whichever way, the woman will pay for infidelity in the relationship as illustrated in the next two extracts from Focus group 3: "... and whenever you realise that that a man is cheating, he takes it out on you"; "Some of them they burn them with the hot water. The boyfriend came over and found the girlfriend with another man [laughter]".

\section{Intimate partner violence is a private and secret phe- nomenon}

The emergency unit is one of those spaces where IPV is visible and recognisable. Participants in all the focus groups mentioned that "sometimes they [women subjected to IPV] do tell us, but others they don't." When asked in Focus group 1 why women are reluctant to disclose IPV, participants related it to "embarrassment".

ENs are knowledgeable about how IPV is concealed.
Sometimes the partner will stay with the woman and talk on her behalf, some women will try to get themselves admitted to hospital, while others will show emotional signs such as crying and anger. The following extracts illustrate the above mentioned: "The lady will come with her husband, and it's the busband who's doing all the talking... so you can see somewhere there is abuse"; "... sometimes they just want to be admitted just to be away from the family or the husband... that is the sign...the first thing she will say: 'Sister I need to be admitted.' 'Why? Are you sick?'... they are running away; ...they are moody... crying all the time... some are violent or rude".

Participants explained the anger as a defence mechanism, a way of maintaining control, rather than breaking the silence and admitting the IPV: “...they develop a defence mechanism...they can't fight the abuser, but if Iam here they feel like they are the stronger person...they defend themselves in a way. They become those people [the abusers]".

The silence surrounding IPV poses a dilemma for ENs, "because we are often not sure about the abuse." Should they maintain the silence and keep the IPV hidden, or should they use their power as healthcare providers to convince the women to disclose the abuse? If the injuries are clearly IPV related, nurses usually ask more probing questions: "Sometimes they just cry and they can't even explain... sometimes you see they have bruises... so most of the time you ask: 'What's happening with the arms there?' She starts to cry, to find out like she's been abused ... maybe after 10 or 15 minutes she will explain it...'My busband beat me and do the stuff."

Most participants felt that the women are responsible to disclose the cause of their injuries to healthcare providers. If they choose to remain quiet, they may face severe consequences. For example, a participant in Focus group 1 revealed that a pregnant woman was admitted to the emergency unit but did not reveal that she had bleeding. On the following day, when she was admitted with a miscarriage, she disclosed the IPV and wanted to press charges against the abuser. She was unable to answer when asked why she did not report the assault the previous day. She could possibly have saved the baby had she resisted the power of the embarrassment that silenced her: "...she came and she went for sonar, she came the following day complaining of bleeding. It then came out that she didn't tell us that she was bleeding the day before. The doctor who examined her, told her: 'You're having a miscarriage. Why didn't you stop 
this miscarriage by telling us about the bleeding yesterday?' She then asked if she can get the person who did it to her arrested, the doctor read the previous notes and asked her why she hadn't reported the assault the previous day. He told her there's nothing we can do now, we can't save the baby. Only the next day did she say the boyfriend kicked her in the stomach, she was seven months pregnant".

\section{Emergency nurses have limited scope to intervene when they encounter women subjected to intimate partner violence}

ENs sometimes feel powerless when confronted with IPV, this participant felt that the only option was to remove the woman from the situation: "... and it is beyond our power to do anything. I mean, I can't go there, I can't take her bome with me".

IPV is often considered to be a personal problem, as a result, women are considered to be responsible for acting or seeking help, rendering ENs powerless to intervene: "You feel sad as a woman... to see such things happening to a woman, but unfortunately you can't fix it, it's up to the person who has been abused'.

ENs manage their interactions with abused women by controlling the objectification of the IPV. To maintain equilibrium, the women's emotions and vivid descriptions of the abuse are silenced: "Advise them, don't ask a lot of questions, you will make things worse, she will end up crying the whole time. You know: 'And then what happened, was he holding a knife?', and she will see the knife. You don't ask a lot of questions, you listen to what she says".

Some nurses are unsure of their actions and see reassurance as their only course of action: "I didn't know what to do, but then I just tried to reassure her." This reassurance was described as "moral support" that attempts to remove the blame from the woman by explaining that the IPV "is not ber fault... she must not blame herself." Participants in all focus groups felt that they were not at liberty to advise women to leave abusive relationships. Such advice may be construed as "judgmental", an attitude that is better avoided in the nurse-patient relationship: "You don't say leave the person, because if you do that, now you are being judgmental. What you can advise: 'You know what my dear, this kind of a relationship is not so nice, it's up to you to decide if you want to live like this or not.' You don't make a decision for the woman..."

IPV was clearly viewed as the domain of the social work- er: "You just advise her to go to the social worker." Participants shared certain institutional barriers to referring women subjected to IPV. Firstly, some nurses did not know where to refer to: "unfortunately, the referral system is terrible, so I didn't know where to refer her to;" and secondly nurses are not allowed to refer patients. When asked about the reason for the latter, nobody was able to clarify the unwritten rule: "Not us, I think the doctor is the one who are supposed to refer them to the social workers, because we can't refer patients as nurses. We don't refer. Unfortunately, but if I had a choice I will refer her'.

Social workers are also only available at certain times and women seldom return to see social workers: "I even took the social worker's number [to give to the woman who was seen after hours]...we don't really have people who can intervene like during the day, we only treat, the doctor sees them and discharge them and they go".

\section{Discussion}

ENs base the care they provide to women exposed to IPV on the discourse, or underlying system of beliefs, that (1) strong women subject themselves to societal expectations and endure IPV, (2) women are vulnerable to and powerless against IPV, (3) IPV is a private and secret phenomenon, and (4) ENs have limited scope to intervene when they encounter women exposed to IPV. These beliefs influence the identification of and possible interventions to women exposed to IPV.

IPV may be viewed through different lenses, for example, the feminist, sociological or nested ecological theory ${ }^{24}$. From a Foucauldian perspective these theories represent different realities and truths, based on knowledge from different historical periods and disciplines. The discourses described by ENs in this study are based on knowledge and practices evident within a South African context.

In South Africa, coercive social norms, that position women as subordinate and subservient to men in the family, prevail ${ }^{25}$. As a result, women often endure IPV silently due to cultural pressure to maintain familial harmony and privacy ${ }^{25}$. Women who tolerate and forgive IPV are respected and admired in certain South African communities ${ }^{26}$. South African women are less likely to return to their parental households due to the belief that they will burden their families. In Foucauldian terms, women 
subject themselves to surveillance discipline defined by cultural and social groups ${ }^{27}$. This discourse also governs ENs' practice; they are unlikely to encourage women to leave abusive relationships and to resist societal expectations.

Women may feel obliged to leave the abusive relationships by the need to protect their children from violence. Internal tension is caused when this need is juxtaposed with their feelings of responsibility for keeping their families together and avoiding legal system involvement ${ }^{28}$. Within a Foucauldian context, this tension constitutes a contradictory and continually shifting relation between a wish to resist and escape the violence and the realisation that they are not "free to act in any way they wish" 29 . ENs (this study) recognised the effects of prolonged stress and tension on the mental health of women exposed to IPV. IPV is associated with increased risk of depression, posttraumatic stress disorder, substance-related disorders, anxiety and suicidality ${ }^{30-32}$.

In Foucauldian terms, power "is embodied or performed through the interplay of non-equal and changing relations of force in a specific context" ${ }^{33}$. ENs in this study were cognisant of the power relations at play in IPV and positioned IPV within traditional power structures of male dominance and female subjectivity ${ }^{34}$. Men satisfy their need for power by making women feel weak, while women's weakness render them powerless against IPV. ENs realised that as women, they could also become recipients of IPV. Paradoxically male power may obscure male feelings of vulnerability. Male vulnerability comes to the fore when resources are limited, for example in poverty-stricken communities. Men feel compelled to compete with other men by controlling women, often through violence ${ }^{35}$.

ENs, in this study, attributed the silence surrounding IPV to feelings of embarrassment which can be explained by the IPV stigmatisation model ${ }^{36}$. The authors proposed three types of stigma. Anticipated stigma refers to the degree to which women fear or expect stigmatization when disclosing IPV. Stigma internalization happens when women internalize negative IPV beliefs invoked by, for example, psychological abuse, victim-blaming, portraying IPV victims as helpless, or devaluations of IPV as shame- ful. Cultural stigma represents societal discourses that diminish IPV experiences. Continued silence or non-disclosure of IPV is a complex process. When a woman exposed to IPV visits the emergency unit, for example, four scenarios may play out ${ }^{37}$. IPV may be recognised and acknowledged by both the woman and the EN, the EN recognises the IPV but the woman does not; the woman recognises the IPV but the EN is unaware, and lastly neither woman nor EN recognises or acknowledges the IPV. Applying Foucault's notion of objectification ${ }^{22}$, the object 'IPV' may thus be uncovered in the emergency unit as visible, so that both women and ENs may think of, speak of, and act upon it; or it may stay hidden.

Women exposed to IPV may fear that disclosure may lead to intrusion by healthcare providers. Intrusion refers to pressure to disclose IPV, leave the relationship or report the IPV to the legal system ${ }^{38}$. Nurses should avoid intrusion by facilitating disclosure of IPV through assessment in a private setting, by being supportive and non-judgemental, showing respect for women's autonomy, and planning with them for their safety ${ }^{37,39-40}$.

ENs, in this study, agreed that the decision to stay in or leave a violent relationship was personal ${ }^{41}$. Participants preferred not to elicit emotional expression and descriptions of the IPV, but rather felt that nurses should comfort these women and try to exempt them from guilt. Similarly, Meyer ${ }^{42}$ explained that rather than judging a woman's decision to stay in the violent relationship as irrational or irresponsible, nurses should understand the complex factors influencing such a decision.

Nurses in this study limited their role to listening to and comforting women exposed to IPV and to reporting the situation to the doctor. The bio-medically oriented model where the doctor manages the treatment plan constrained ENs from referring women to social workers. Limiting their role may reflect a discourse that nurses are not supposed to intervene in IPV and have limited scope to do so. Some nurses indicated their desire to help but did not know what to do, a powerless feeling common to IPV victims and healthcare providers. The feelings of powerlessness may be due to knowledge and practice gaps regarding responses to $\mathrm{IPV}^{13}$. Although women exposed to IPV are apparently powerless, Campbell and Mannell ${ }^{25}$ 
illustrated how these women seek opportunities for agency. They attempt to manage and survive IPV amidst the challenges they face on a daily basis. Agency is enacted through access to legal, welfare, healthcare and other services, and supportive social relationships and networks. Agency across space include opportunities to move away from the violent situation, and women's position in relation to local and global responses to IPV. From a Foucauldian perspective, agency may be interpreted as resistance. Women employ different resources and strategies to pursue resistance located at the level of their daily lives $^{29}$. EN's are present when women reach out for help immediately following abusive episodes.

\section{Conclusion}

The study has limitations. The South African population is known for its ethnic and cultural diversity. Since culture may shape discourses, the researcher should have mentioned the cultural groups participants belonged to, and should have included nurses from different cultural groups. Only nurses participated in the study; future studies should include other healthcare professionals, for example, doctors who are exposed to similar situations

The discourses surrounding IPV in South Africa are largely pre-modern. The same discourses that subject women to IPV, namely, maintaining silence and accepting that they are powerless against IPV, may influence ENs' decisions not to intervene. However, sometimes ENs are alert of and question the visible and not so visible signs of IPV, and interpret the women's feelings. When deciding to intervene, some ENs provide emotional support, but feel powerless to do anything but to discharge the woman, knowing that the IPV will not stop. Some may alert the doctor for referral to social workers.

The question is how ENs can challenge discourses that reinforce and sustain IPV ${ }^{43}$. Participants in the study, though in a subtle way, expressed themselves against the cultural and parental domination prescribing women to tolerate IPV. ENs are in a position to use, what Armstrong and Murphy ${ }^{29}$ explained as resistance on a conceptual level. They may, for example, question the way in which women subject themselves to IPV. This form of resistance has the potential to transform discourses that normalise IPV. Springer and Clinton ${ }^{44}$ challenged nurses to address " ...the social inequalities that result in the prejudices that disempower the recipients of our care even more than ourselves." ENs are in a position to intervene in IPV through portraying a non-judgmental approach that lay the foundation for disclosure ${ }^{45}$, incorporating understanding of turning points to support women to change their IPV situations ${ }^{46}$, documentation, referral and safety planning ${ }^{47}$.

\section{Conflict of interest}

None declared.

\section{References}

1. Sprague S, Goslings C, Hogentoren C, de Milliano S, Simunovic N, Madden $K$, et al. Prevalence of intimate partner violence across medical and surgical health care settings: A systematic review. Violence Against Women. 2014:20(1):118-36.

2. Reisenhofer S, Seibold C. Emergency healthcare experiences of women living with intimate partner violence. Journal of Clinical Nursing. 2012:22:2253-63.

3. World Health Organization. Understanding and addressing violence against women. Intimate partner violence. Geneva: World Health Organization; 2012. Available from: http://apps.who.int/iris/bitstream/10665/77432/1/WHO_RHR_12.36_eng.pdf

4. García-Moreno C, Hegarty K, d'Oliveira AF, Koziol-MacLain J, Colombini M, Feder G. The health-systems response to violence against women. Lancet. 2014:18(285):1567-79.

5. Walton LM, Aerts F, Burkhart H, Terry T. Intimate partner violence screening and implications for health care providers. Online Journal of Health Ethics. 2015:11(1) Available from: http://dx.doi.org/10.18785/ojhe.1101.05 6. Zijlstra E, van de Laar R, Moors ML, Lo Fo Wong, S, Lagro-Janssen A. Tensions and ambivalent feelings opinions of emergency department employees about the identification and management of intimate partner violence. Journal of Interpersonal Violence. 2015:32(7): 1044-67. 7. Vonkeman J, Atkinson P, Fraser J, McCloskey R. Do emergency department staff use a current domestic violence documentation tool or other forms of intimate partner violence documentation in patient records? Canadian Journal of Emergency Medicine. 2017:19(S1):S66-S66. 8. Beynon CE, Gutmanis IA, Tutty LM, Wathen CN, MacMillan HL. Why physicians and nurses ask (or don't) 
about partner violence: A qualitative analysis. BMC Public Health. 2012:12(473):1-12.

9. Sundborg EM, Saleh-Stattin N, Wändell P, Törnkvist L. Nurses' preparedness to care for women exposed to intimate partner violence: A quantitative study in primary health care. BMC Nursing. 2012:11(1). Available from: http:/ /www.biomedcentral.com/1472-6955/11/1

10. Husso M, Virkki T, Notko M, Holma J, Laitila A, Ma“ntysaari M. Making sense of domestic violence intervention in professional health care. Health and Social Care in the Community. 2012:20(4):347-55.

11. Van der Wath A, van Wyk N, Janse van Rensburg E. Emergency nurses' experiences of caring for survivors of intimate partner violence. Journal of Advanced Nursing. 2013:69(10):2242-52.

12. Koistinen I. Positions constructed in specialist health care for patients experiencing intimate partner violence [dissertation]. Finland: University of Jyväskylä; 2012.

13. Roush K, Kurth A. Intimate partner violence: The knowledge, attitudes, beliefs, and behaviors of rural health care providers. American Journal of Nursing. 2016:116(6):24-34. p. 31.

14. Foucault M. The archaeology of knowledge (A. M. Sheridan Smith, Trans.). New York: Pantheon Books; 1972. p. 138

15. Hall S. The work of representation. In Hall S, editor. Representation: cultural representations and signifying practices. London: Sage, in association with the Open University; 1997. p. 15-64

16. Whisnant CJ. Foucault \& discourse: A handout for HIS 389. 2012. Available from: http://webs.wofford. edu/whisnantcj/his389/foucualt_discourse.pdf

17. Westlund AC. Pre-Modern and modern power: Foucault and the case of domestic violence. Signs. 1999:24(4):1045-66.

18. Rispel L. Analysing the progress and fault lines of health sector transformation in South Africa. In: Padarath A, King J, Mackie E, Casciola J, editors. South African Health Review. Durban: Health Systems Trust; 2016. p. 1724.

19. Parahoo K. Nursing research: Principles, process and issues. 3rd ed. Houndmills, UK: Palgrave Macmillan; 2016.

20. Wiggins S, Riley S. Discourse analysis. In: Forrester M, editor. Doing qualitative research in psychology: A practical guide. London: Sage; 2010. p. 135-53

21. Hodges BD, Kuper A, Reeves S. Qualitative research.
Discourse analysis. BMJ. 2008:337:570-576.

22. Fadyl JK, Nicholls DA, McPherson KM. Interrogating discourse: The application of Foucault's methodological discussion to specific inquiry. Health. 2013:17(5):47894.

23. Willig C. Introducing qualitative research in psychology. 3rd ed. Buckingham, UK: Open University Press; 2013.

24. Ali PA, Naylor PB. Intimate partner violence: A narrative review of the feminist, social and ecological explanations for its causation. Aggression and Violent Behavior. 2013:18:611-19.

25. Campbell C, Mannell J. Conceptualising the agency of highly marginalised women: Intimate partner violence in extreme settings. Global Public Health. 2016:11(1-2):116.

26. Jewkes R, Morrell R. Gender and sexuality: Emerging perspectives from the heterosexual epidemic inSouth Africa and implications for HIV risk and prevention. Journal of the International AIDS Society. 2010:13(6). Available from: https://www.ncbi.nlm.nih.gov/pmc/articles/ PMC2828994/

27. Foucault M. The ethics of the concern for self as a practice of freedom. In: Lotringer S, editor. Foucault live: Collected interviews 1961-1984. New York: Semiotex$\mathrm{t}(\mathrm{e})$; 1984. p. 432-49.

28. Rhodes KV, Cerulli C, Dichter ME, Kothari CL, Barg FK. "I didn't want to put them through that": The influence of children on victim decision-making in intimate partner violence cases. Journal of Family Violence. 2010:25:485-93.

29. Armstrong N, Murphy E. Conceptualizing resistance. Health. 2011:16(3):314-326. p. 316

30. Devries KM., Mak JY, Bacchus LJ, Child JC, Falder $G$, Petzod M, et al. Intimate partner violence and incident depressive symptoms and suicide attempts: A systematic review of longitudinal studies. PloS Med. 2013:10(5):111. Available from: http://journals.plos.org/plosmedicine $/$ article $/$ file?id $=10.1371$ / journal.pmed.1001439\&type $=$ printable

31. Lagdon S, Armour C, Stringer, M. Intimate partner violence and mental health adult experience of mental health outcomes as a result of intimate partner violence victimisation: A systematic review. European Journal of Psychotraumatology. 2014:5. Available from: https://www.ncbi. nlm.nih.gov/pmc/articles/PMC4163751/

32. Wong J. Mellor D. Intimate partner violence and 
women's health and wellbeing: Impacts, risk factors and responses. Contemporary Nurse. 2014:46(2):170-79.

33. Powers P. The philosophical foundations of Foucaultian discourse analysis. Critical Approaches to Discourse Analysis across Disciplines. 2007:1(2):18-34. p. 30.

34. Black BM, Weisz AN, Bennet LW. Graduating social work students' perspectives on domestic violence. Journal of Women and Social Work. 2010:25(2):173-84.

35. Morrell R, Jewkes R, Lindegger G. Hegemonic masculinity/masculinities in South Africa: Culture, power, and gender politics. Men and Masculinities. 2012:15(1):1130 .

36. Overstreet NM, Quinn DM. The intimate partner violence stigmatization model and barriers to help-seeking. Basic and Applied Social Psychology. 2013:35(1):109-22.

37. Bradbury-Jones C, Taylor J, Kroll T, Duncan F. Domestic abuse awareness and recognition among primary healthcare professionals and abused women: A qualitative investigation. Journal of Clinical Nursing. 2014:23:3057-68. 38. Catallo C, Jack SM, Ciliska D, MacMillan HL. Minimizing the risk of intrusion: A grounded theory of intimate partner violence disclosure in emergency departments. Journal of Advanced Nursing. 2012:69(6):1366-76.

39. O’Doherty L, Hegarty K, Ramsay J, Davidson LL, Feder G, Taft A. Screening women for intimate partner violence in healthcare settings. Cochrane Database of Systematic Reviews. 2015:7(Art.No.:CD007007):1-103.

40. Spangaro J, Koziol-McLain J, Zwi A, Rutherford A, Frail M, Ruane J. Deciding to tell: Qualitative configurational analysis of decisions to disclose experience of intimate partner violence in antenatal care. Social Science \& Medicine. 2016:154:25-53.

41. Shorey RC, Tirone V, Nathanson AM, Handsel VA, Rhatigan DL. A preliminary investigation of the influence of subjective norms and relationship commitment on stages of change in female intimate partner violence victims. Journal of Interpersonal Violence. 2013:28(3):621-42. 42. Meyer S. Why women stay: A theoretical examination of rational choice and moral reasoning in the context of intimate partner violence. Australian \& New Zealand Journal of Criminology. 2012:45(2):179-93.

43. Thapar-Björkert S, Morgan KJ. "But sometimes I think ... they put themselves in the situation": Exploring blame and responsibility in interpersonal violence. Violence against Women. 2010:16(1):32-59.

44. Springer RA, Clinton ME. Doing Foucault: inquiring into nursing knowledge with Foucauldian discourse analysis. Nursing Philosophy. 2015:16:87-97. p. 93

45. Wilson D. Practising with our hearts and minds: Nurses and intimate partner violence. Journal of Clinical Nursing. 2015:24:2055-56.

46. Chang JC, Dado D, Hawker L, Cluss PA., Buranosky $\mathrm{R}$, Slagel L. et al. Understanding turning points in intimate partner violence: Factors and circumstances leading women victims toward change. Journal of Women's Health. 2010:19(2):251-59.

47. Roark SV. Intimate partner violence: Screening and intervention in the health care setting. The Journal of Continuing Education in Nursing. 2010:41(11):490-95. 